\title{
THE LUNG AS A BLACK BOX*
}

\section{J. F. NUNN, PH.D., M.B., GH.B., F.F.A.R.c.s. $†$}

ACCORDING TO CURRENT USAGE, a "black box" is a process or device whose internal workings are not understood by the operator, but whose function is important and may be studied in detail without appreciation of the internal mechanism. A typical example of a black box is the television receiver which is understood by very few of the population although its performance is important to the viewer. Most of us dislike operating black boxes since it is intellectually unsatisfying and, on the practical level, places us in a position of great vulnerability if the mechanism should fail. However, at some period during the industrial revolution it became impossible for all men to understand the workings of everything they used and, from that date, we have become surrounded by an ever-increasing number of black boxes. Furthermore, we may confidently predict that the trend will increase as simple devices are replaced by their more complicated successors.

We customarily think of a black box as being constructed by an individual or group of individuals who possess greater or more specialized knowledge than ourselves. Without entering on theological considerations, it is clear that the human body and its constituent organs fall within the definition of black boxes. It is true that we know something of their mode of action, but the great advances in physiology of the last century have also given us glimpses of the great complexity of living organisms. It appears that the day is far distant when we can presume to understand life in its entirety.

These considerations should not discourage us in our pursuit of knowledge, and the burden of my lecture is to use the example of the lung to demonstrate how we can base our management of patients on the function of organs considered as black boxes.

Perhaps the simplest major organ in the body is the lung. At present it seems as though the lung functions predominantly as a physical system, with gases and blood flowing through tubes according to physical laws and with constituent gases passing from one phase to another in accordance with partial pressure gradients. It is in fact possible to construct man-made models of the lung which will function temporarily for the maintenance of gas exchange during cardiopulmonary bypass. However, the function of these devices is ultimately limited by structural considerations, and it is in the field of dimensions and structural integrity that the lung stands out in contrast to man-made substitutes.

The anaesthetist is more deeply involved in the function of the lung than is almost any other practitioner of medicine. He is constantly concerned with the function of the lung before, during, and after anaesthesia, and in the great majority of patients who are treated in intensive care units. Most of his patients show malfunction of the lung to some degree but fortunately he possesses, to a

The seventh Dr. Harry Shields Lecture, University of Toronto, December 10, 1965.

†Professor of Anaesthesia, University of Leeds.

81

Can. Anaes. Soc. J., vol. 13, no. 2, March, 1966 
truly remarkable extent, the means of influencing the exchange of gases within the lungs. He may alter the ventilation within wide limits, institute artificial ventilation, alter the composition of the inspired gas mixture, alter the patient's metabolic rate, even alter the ambient pressure, and as a final resort institute an extra-corporeal cardio-pulmonary bypass. In few specialties has the practitioner more powerful therapeutic tools, and the time scale of the changes induced is of another order of magnitude in comparison with activities in almost any other branch of medicine.

\section{Functional Modeis of the Lung}

To understand the performance of a black box it is useful to consider a model system which can be elaborated as our understanding of the device increases. It is not essential that the model should operate in the same way as the original system, but the model must have the same over-all function as the original. Thus, for the same input, the output of model and original systems must be identical, within the limits of our ability to assess function.

All anaesthetists are familiar with the flask-shaped alveolus popularized as a simple lung model by the authors of "The Lung." The function represented by this device is the exchange of oxygen and carbon dioxide between the perfusing pulmonary blood flow and the alveolar ventilation. Alveolar levels of $P_{\mathrm{O}_{2}}$ and $P_{\mathrm{CO}_{2}}$ are dependent upon the interplay of barometric pressure, inspired gas composition, alveolar ventilation, and the uptake and output of $\mathrm{O}_{2}$ and $\mathrm{CO}_{2}$ respectively. The relationships are strictly quantitative and have been incorporated in a special-purpose slide rule. ${ }^{2}$

$$
P_{\mathrm{A} \mathrm{CO}}=\left(P_{\mathrm{B}}-P_{\mathrm{H}_{2} \mathrm{O}}\right)\left(F_{\mathrm{ICO}_{2}}+\dot{V}_{\mathrm{CO}_{2}} / \dot{V}_{\mathrm{A}}\right)
$$

and

$$
P_{\mathrm{A} \mathrm{O}_{2}}=\left(P_{\mathrm{B}}-P_{\mathrm{H}_{2} \mathrm{O}}\right)\left(F_{\mathrm{O}_{2}}-\dot{V}_{\mathrm{O}_{2}} / \dot{V}_{\mathrm{A}}\right)^{\circ}
$$

If we consider the barometric pressure, $\mathrm{O}_{2}$ uptake, and $\mathrm{CO}_{2}$ output to be constant, these relationships may be satisfactorily displayed on a graph (Fig. 1). This graph forms a useful guide to the effect of changes in ventilation and composition of inspired gas. It shows clearly the non-linear relationship between ventilation and alveolar gas tensions and permits calculation of the effect of alterations in the concentration of oxygen in the inspired gas. If we make the

\footnotetext{
- Symbols are in accord with the recommendations of the Committee for Standardization of Definitions and Symbols in Respiratory Physiology. ${ }^{3}$

Primary symbols

$V$ gas volume

$\dot{V}$ gas flow rate or exchange

$F$ fractional concentration

$P$ tension

$R$ respiratory exchange ratio

$f$ respiratory frequency
}

The relationships in these equations are not precisely true, since no account is taken of the small differences in volume of inspired and expired gas. 


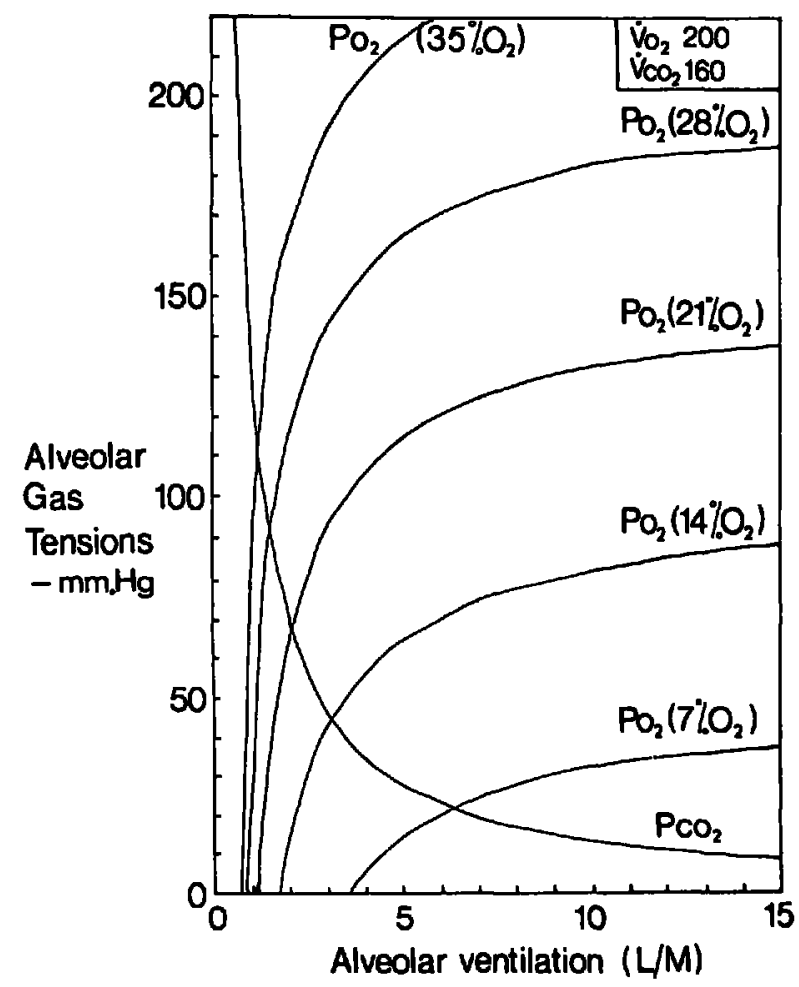

Figure 1. Relationship between alveolar gas tensions and alveolar ventilation for various concentrations of oxygen in the inspired gas mixture. It is assumed that the inspired $\mathrm{CO}_{2}$ concentration is zero and that the barometric pressure is $760 \mathrm{~mm} . \mathrm{Hg}$. Assumed values for oxygen consumption and $\mathrm{CO}_{2}$ output are indicated on the diagram.

reasonable assumption that the $P_{\mathrm{O}_{2}}$ and $P_{\mathrm{CO}_{2}}$ of the pulmonary end-capillary blood is approximately equal to the alveolar tensions, we may use our model to indicate the effect of various factors on the gas tensions of the arterial blood.

The simple lung model has considerable application to the conscious healthy subject, but is not adequate to describe the function of the lungs of patients who are under the care of anaesthetists, whether in the operating theatre or in the intensive care unit. The simple model portrays a single alveolus and carries the assumption that every functional unit in the lung behaves in an identical manner. It is now clear that this is not true during anaesthesia, and we must therefore postulate a more complex model which is shown in Figure 2.

Within the black box are shown five functional units which together are sufficient to represent the function of the lung in the disordered state in which it is usually seen by the anaesthetist. Each unit may be conveniently represented by its ventilation/perfusion $(V / Q)$ ratio. The over-all ventilation/perfusion ratio of the lung is about 0.85 in the resting healthy subject. It is raised in hyperventilation or hypoperfusion (both abnormalities occurring in low-output

- Ventilation/perfusion ratio is commonly abbreviated to $V / Q$ or, more correctly, $\dot{V}_{\Delta} / \dot{Q}$. The Pappenheimer symbol $\dot{V}_{A}$ means alveolar ventilation and $\dot{Q}$ means perfusion. 


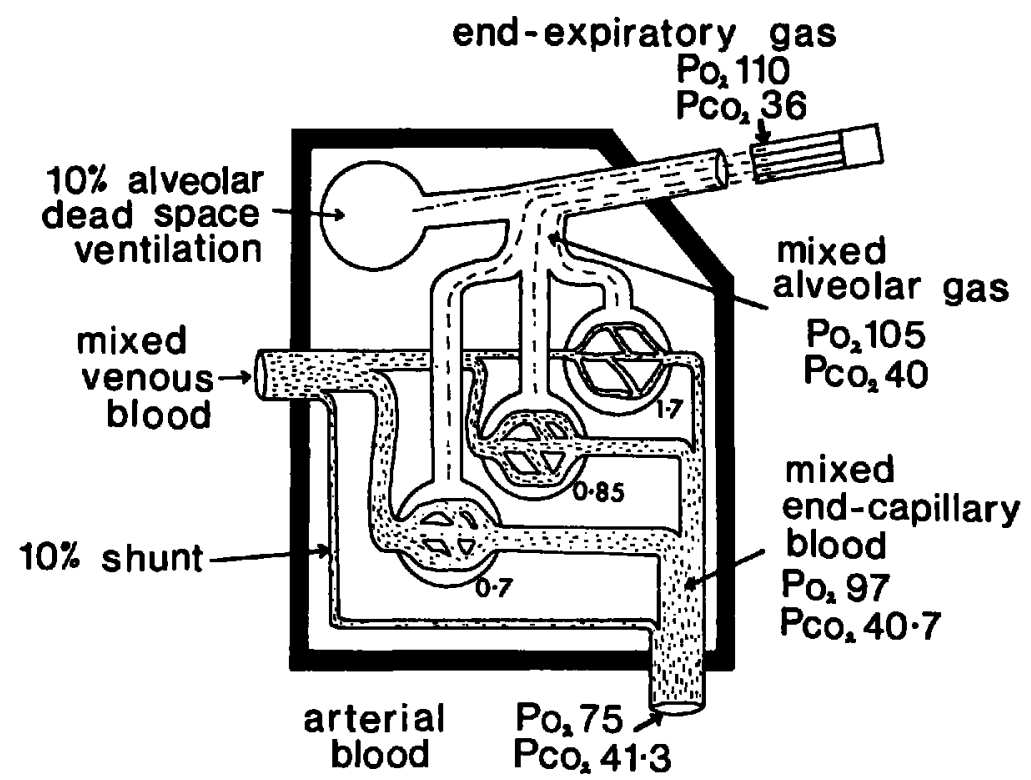

Figure 2. A lung model incorporating the abnormalities of distribution which are believed to occur during anaesthesia. The values for $P_{\mathrm{O}_{3}}$ and $P_{\mathrm{CO}}$ are typical for a patient breathing 21 per cent oxygen with a normal alveolar ventilation. The arterio-venous oxygen content difference is assumed to be 5 vols. per cent.

cardiac failure such as occurs after haemorrhage). Over-all $V / Q$ ratio is lowered in hypoventilation or increased perfusion without hyperventilation.

In the top left-hand corner of the black box is shown an alveolus which is ventilated but not perfused. The ventilation/perfusion ratio is thus infinity. In the normal subject this probably represents the condition of the supraclavicular parts of the lungs where the pressure in the pulmonary arterioles is less than atmospheric, resulting in collapse of the pulmonary capillaries. Under pathological conditions, failure of perfusion may result from embolization of vessels, from destruction of vessels, and also from ventilation of spaces at the alveolar level which are devoid of blood vessels. During anaesthesia there is appreciable ventilation of unperfused spaces for reasons which are still not clear. It might be thought that the supine position would reduce the effect of gravity, but recent studies by Askrog (personal communication) have shown that the magnitude of the effect is inversely related to the pulmonary arterial pressure, suggesting that gravity is responsible.

Areas at alveolar level with a ventilation/perfusion ratio of infinity may be termed alveolar dead space. They tend to reduce the ventilation to those alveoli which are perfused and in which gas exchange takes place. Alveolar dead space is thus a constituent of the physiological dead space. However, it does not follow that an increased alveolar dead space will inevitably result in a diminution of alveolar ventilation. If the minute volume is fixed (as in the case of a patient on a ventilator) then the development of an alveolar dead space must reduce the alveolar ventilation. However, if respiration is spontaneous, the patient is very likely to increase his minute volume and so maintain his alveolar ventilation. 
This is, in fact, what usually happens when the alveolar dead space is increased by haemorrhage or by pulmonary embolization.

It will also be apparent from Figure 2 that alveolar dead space gas mixes with gas from perfused alveoli during expiration. Since the alveolar dead space contains gas which approximates to inspired gas in composition, the end-expiratory gas will have a lower $P_{\mathrm{CO}_{2}}$ and a higher $P_{\mathrm{O}_{2}}$ than the mixed gas from the alveoli which are perfused. The difference between the alveolar and the end-expiratory gas tensions is of the same order for oxygen and carbon dioxide. However, the difference is more conspicuous for carbon dioxide than for oxygen since the alveolar $P_{\mathrm{O}_{2}}$ is normally larger than the alveolar $P_{\mathrm{oO}_{2}}$. The latter is also more easily derived and it has therefore become customary to consider alveolar dead space ventilation in terms of the alveolar/end-expiratory $P_{\mathrm{CO}_{2}}$ difference. Furthermore, we shall see that the $P_{\mathrm{O}_{2}}$ is markedly influenced by other factors which have little effect on $P_{\mathrm{CO}_{2}}$. A 10 per cent alveolar dead space will reduce an alveolar $P_{\mathrm{CO}_{2}}$ of $40 \mathrm{~mm}$. $\mathrm{Hg}$ to $36 \mathrm{~mm}$. $\mathrm{Hg}$ and raise an alveolar $P_{\mathrm{O}_{2}}$ of $105 \mathrm{~mm}$. $\mathrm{Hg}$ to $110 \mathrm{~mm}$. Hg. Alveolar dead space may also be quantified by showing that the physiological dead space is bigger than the measured (or assumed) anatomical dead space.

If we now move to the bottom left-hand corner of the black box in Figure 2, we see the shunt from pulmonary artery to pulmonary vein. The ventilation/ perfusion ratio of a shunt is zero. In the normal subject, part of the bronchial flow together with the venae cordis minimae of the left heart constitute a shunt, although we should note that they do not contribute mixed venous blood to the arterial stream, but blood which is usually considerably more desaturated than pulmonary arterial blood. This point is often overlooked in calculating "shunts." Under pathological circumstances, shunts can result from atelectasis, sequestration of gas in obstructed parts of the lung, froth-filled alveoli, and blood flow through contused and damaged alveoli. We are also interested in the possibility of direct pulmonary arterio-venous shunting through the communications which have been demonstrated by von Hayek. 4 Whatever the cause, the effect of a shunt is to pull the composition of the arterial blood back towards the composition of venous blood. The effect on individual gas tensions depends on the magnitude of the venous admixture and on the individual mixed venous/arterial gas tension differences. The mixed venous/arterial $P_{\mathrm{O}_{2}}$ difference is of the order of $60 \mathrm{~mm} . \mathrm{Hg}$ in the normal subject and only about one tenth of this for $P_{\mathrm{OO}_{2}}$. Therefore venous admixture has a much larger effect upon the arterial $P_{\mathrm{O}_{2}}$ than on the arterial $P_{\mathrm{CO}_{2}}$. The actual calculation is tedious since mixing equations involve content and not tension of blood gases. It is therefore necessary to convert tensions to contents, then to calculate the effect of the venous admixture on arterial gas contents, and finally to convert back to tensions. Since the calculation is influenced by the oxygen capacity of the blood, the arterio-venous difference, and the shift of the dissociation curve caused by $\mathrm{pH}$ and $\mathrm{P}_{\mathrm{CO}_{2}}$, it will readily be appreciated that the calculation is excessively laborious. In our own department, a computer programme has been compiled for its solution. As a typical example (Table I) we may consider 10 per cent venous admixture occurring in a patient with arteriovenous oxygen difference of 5 vols. per cent and an oxygen capacity of 20 vols. 
TABLE I

EFfect of 10 PER CENT Shunt

\begin{tabular}{lcc}
\hline & $P_{\mathrm{O}_{2}}(\mathrm{~mm} . \mathrm{Hg})$ & $P_{\mathrm{Cog}_{2}(\mathrm{~mm} . \mathrm{Hg})}$ \\
\hline Pulmonary & & \\
End-capillary blood & 97 & 40.7 \\
Arterial blood & 75 & $\mathbf{4 1 . 3}$ \\
\hline
\end{tabular}

per cent (i.e. haemoglobin concentration of $14.8 \mathrm{gm} . / 100 \mathrm{ml}$.). In contrast to the alveolar dead-space effect, mentioned above, the venous admixture effect has a conspicuous effect upon $P_{\mathrm{O}_{2}}$ but little effect upon $P_{\mathrm{CO}_{2}}$.

We may now turn our attention to the three alveoli in Figure 2, which are both perfused and ventilated. These alveoli do not all have the same ventilation and perfusion. They represent the upper, middle, and lower zones of the lungs in the normal upright subject and, from the data of West, ${ }^{5}$ the conditions in these three zones are shown in Table II, in round figures. It is quite likely that these

TABLE II

\begin{tabular}{lccc}
\hline \hline & Mean ventilation/perfusion ratio & $\begin{array}{c}\text { Percentage } \\
\text { contribution } \\
\text { to total } \\
\text { ventilation }\end{array}$ & $\begin{array}{c}\text { Percentage } \\
\text { contribution } \\
\text { to total } \\
\text { perfusion }\end{array}$ \\
\hline $\begin{array}{l}\text { Upper zone } \\
\text { Middle zone }\end{array}$ & $\mathbf{1 . 7}$ & 20 & 10 \\
Lower zone & $\mathbf{0 . 8 5}$ & 35 & 33 \\
\hline
\end{tabular}

figures do not apply under the conditions of anaesthesia since, in the supine subject, it is known that there are no large variations of $V / Q$ ratio between upper and lower zones. However, it seems likely that instead there will be horizontal stratification of $V / Q$ ratios between anterior and posterior parts of the lung. Therefore, in the absence of any quantitative data obtained during anaesthesia, it has seemed reasonable to use the data of West.

From these figures it is possible to calculate the $P_{\mathrm{O}_{2}}$ and $P_{\mathrm{CO}_{2}}$ of each zone and, by solution of mixing equations, to determine the $P_{\mathrm{O}_{2}}$ and $P_{\mathrm{oO}_{2}}$ of mixed alveolar gas and mixed end-capillary blood, on the assumption that there is no significant gradient between gas tensions of alveolar gas and end-capillary blood for individual alveoli. We find that the scatter of $V / Q$ ratios in our model result in the tension gradients shown in Table III. It will be clear that the gradient for oxygen is appreciable while the value of $P_{\mathrm{CO}_{2}}$ is so small that it could scarcely be

TABLE III

EFFECT OF V/Q SCATtER

\begin{tabular}{lcc}
\hline & $\begin{array}{c}P_{\mathrm{O}} \\
(\mathrm{mm} . \mathrm{Hg})\end{array}$ & $\begin{array}{c}P_{\mathrm{co}} \\
\left(\mathrm{mm} . \mathrm{Hg}_{\mathrm{g}}\right)\end{array}$ \\
\hline $\begin{array}{l}\text { Mixed alveolar gas } \\
\text { Mixed pulmonary } \\
\text { end-capillary blood }\end{array}$ & 105 & 40.0 \\
\hline
\end{tabular}


measured with confidence, a result broadly similar to that produced by venous admixture (Table I).

It is not immediately apparent why the scatter in $V / Q$ ratios produces alveolar/ arterial gas-tension gradients. At first sight, it might be thought that the overperfused alveoli would compensate for the under-perfused alveoli. This is not the case for two reasons. Firstly, the over-perfused alveoli contribute more blood to the arterial stream than the under-perfused alveoli. Therefore there is more sub-oxygenated blood to offset the benefit from the smaller quantity of super-oxygenated blood from the under-perfused alveoli. The second reason for the gradient is the curvature of the oxygen dissociation curve at the values under consideration. This means that if alveolar oxygen tension values are scattered symmetrically around a mean value, there will be an asymmetrical distribution of the saturation of the end-capillary blood. Figure 3 shows how this effect can result

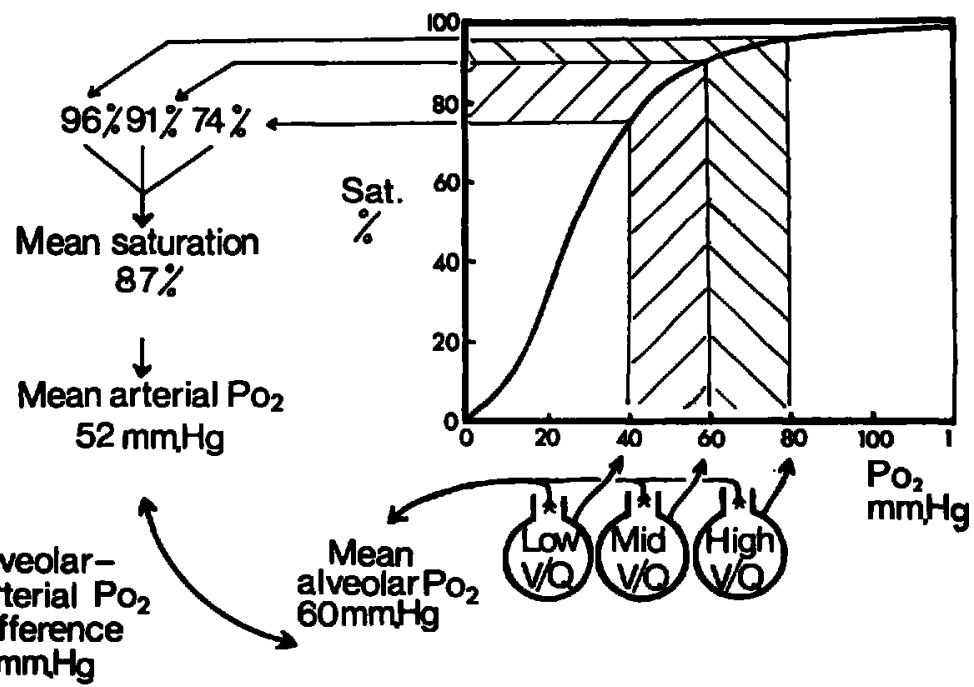

Figure 3. The curvature of the oxygen dissociation curve results in an alveolar/arterial $P_{\mathrm{O}_{2}}$ gradient when there is a scatter of $V / Q$ ratios. In this diagram, no account has been taken of the relative contribution of each group of alveoli to the alveolar gas and arterial blood. Differences in contributions would increase the gradient above the level shown in this diagram. The effect of the curvature of the disscciation curve is maximal at its upper inflection (approximately $P_{\mathrm{O}_{2}}=40 \mathrm{~mm} . \mathrm{Hg}$ ) and therefore the effect of scatter of $V / Q$ ratios is most marked when the alveolar $P_{\mathrm{O}_{2}}$ falls below the normal range.

in an alveolar/arterial $P_{\mathrm{O}_{2}}$ gradient even if we totally disregard the effect of the differences in contributions considered above. The effect shown in Figure 3 will clearly become more marked the nearer the mixed alveolar $P_{\mathrm{O}_{2}}$ is to the point of maximum inflection of the dissociation curve. ${ }^{6}$ This is at a $P_{\mathrm{O}_{2}}$ of about $40 \mathrm{~mm}$. $\mathrm{Hg}$, and the effect of a given degree of $V / Q$ scatter on alveolar/arterial $P_{\mathrm{O}_{2}}$ gradient will increase as the mixed alveolar $P_{\mathrm{O}_{2}}$ falls towards $40 \mathrm{~mm}$. $\mathrm{Hg}$.

The alveolar/arterial $P_{\mathrm{O}_{2}}$ gradient of $8 \mathrm{~mm}$. $\mathrm{Hg}$ which results from the $V / Q$ scatter in our model could be caused by shunting or by alveolar dead-space ventilation. If we remain outside the black box and consider an alveolar/arterial 
$P_{\mathrm{O}_{2}}$ gradient of $8 \mathrm{~mm}$. Hg we can interpret this change by any one of the following: (a) The degree of scatter of $V / Q$ ratio known to occur in the normal upright subject; (b) a shunt of 2 per cent; (c) an alveolar dead space of 15 per cent; (d) simultaneous presence of two or more of these malfunctions.

We can immediately discount the possibility of an alveolar dead space making a large contribution to the $P_{\mathrm{O}_{2}}$ gradient, as it would also result in a $\mathrm{P}_{\mathrm{CO}_{2}}$ gradient of about $6 \mathrm{~mm}$. $\mathrm{Hg}$, which is about ten times the $P_{\mathrm{CO}_{2}}$ gradient which actually results from our scatter of $V / Q$ ratios. We cannot, however, so easily distinguish between $V / Q$ scatter and shunt although the former does produce a $\mathbf{P}_{\mathbf{C O}_{2}}$ gradient which is relatively larger. Distinction between $V / Q$ scatter and shunt must in practice depend upon other methods which are considered below.

We may now fit together the component malfunctions into our model system and consider gas tensions at five levels. Progressive gradients are found for $P_{\mathrm{O}_{2}}$ and $P_{\mathrm{OO}_{2}}$ in opposite directions (Table IV). Values within the box cannot be

TABLE IV

\begin{tabular}{lcc|}
\hline \hline & $\begin{array}{c}P_{\mathrm{O}_{2}} \\
(\mathrm{~mm} . \mathrm{Hg})\end{array}$ & $\begin{array}{c}P_{\mathrm{CO}_{2}} \\
(\mathrm{~mm} . \mathrm{Hg})\end{array}$ \\
\hline Air & 150 & 0 \\
End-expiratory gas & 110 & 36.0 \\
\hline $\begin{array}{l}\text { Mixed alveolar gas } \\
\text { (not contaminated with } \\
\text { alveolar dead space gas) } \\
\begin{array}{l}\text { Mixed pulmonary end- } \\
\text { capillary blood (not } \\
\text { contaminated with } \\
\text { shunted blood) }\end{array}\end{array}$ & 105 & 40.0 \\
\hline Arterial blood & 97 & 40.7 \\
\hline
\end{tabular}

directly measured since only arterial blood and end-expiratory gas can be sampled.

Having completed a model which approximates fairly closely the conditions which we believe to apply during anaesthesia, we may now consider how we can assess the function of our black box from the outside without having a detailed knowledge of the precise malfunction within. Our method of analysis is based on the concept of the ideal alveolar air, ${ }^{7}$ and follows the analytical approach of Riley and Cournand. ${ }^{8}$ The subject has recently been reviewed by Rahn and Farhi. ${ }^{\circ}$

Since we cannot sample mixed alveolar gas before contamination with alveolar dead space gas, we postulate the existence of ideal alveolar gas which has the following characteristics:

1. $P_{\mathrm{CO}_{2}}$ of ideal alveolar gas is assumed equal to that of arterial blood.

2. Respiratory exchange ratio of ideal alveolar gas (relative to inspired gas) is assumed to be the same as that of expired gas (relative to inspired gas).

The $P_{\mathrm{CO}_{2}}$ of our postulated ideal alveolar gas in the example shown in Figure 2 will thus be $41.3 \mathrm{~mm}$. $\mathrm{Hg}$. By solution of the alveolar air equation the ideal alveo$\operatorname{lar} P_{\mathrm{O}_{2}}$ is calculated to be $101 \mathrm{~mm}$. $\mathrm{Hg}$. These values are within a few millimetres of mercury of the actual values for mixed alveolar gas in our model lung. 
The next stage in our analysis is to determine the alveolar dead-space ventilation and the shunt from comparison of gas tensions of end-expiratory gas, ${ }^{*}$ ideal alveolar gas, and arterial blood. We do not attempt to measure the scatter of $V / Q$ ratios because this does not appear practicable in the clinical field at the present time. We therefore measure the degree of alveolar dead space and shunt which would be sufficient to account for the observed gas-tension gradients if alveolar dead space and shunt were the only forms of malfunction. In our model lung (Fig. 2) these calculations indicate an alveolar dead space ventilation of 13 per cent and a shunt of 11 per cent which may be compared with the malfunction built into our model. It will be seen from Table $V$ that the Riley-

TABLE V

\begin{tabular}{lcc}
\hline & $\begin{array}{c}\text { Malfunction built } \\
\text { into model }(\%)\end{array}$ & $\begin{array}{c}\text { Malfunction estimated } \\
\text { by Riley-Cournand } \\
\text { analysis (\%) }\end{array}$ \\
\hline $\begin{array}{l}\text { Alveolar dead space } \\
\text { ventilation } \\
V / Q \text { scatter equal to } \\
\text { that found in normal } \\
\text { upright subject }\end{array}$ & $\begin{array}{l}\text { Equivalent to } \\
\text { shunt of } 2 \% \text { and } \\
\text { dead space of } \\
\text { Shunt }\end{array}$ & $1.5 \%$ \\
\hline
\end{tabular}

Cournand analysis gives a satisfactory estimation of the real alveolar dead-space ventilation and the shunt, while the effect of $V / Q$ scatter is indicated as a small increase in the calculated alveolar ventilation and shunt. We do not measure the actual dead space ventilation and shunt, but the amount of these abnormalities which would be required to give the observed gas-tension gradients. It therefore seems wrong to use the word shunt in this sense, and instead we use the term "calculated venous admixture." Similar semantic difficulties apply to the term "alveolar dead space," but suitable alternative suggestions have not been advanced. The purist might prefer to say "alveolar dead-space-like effect." However, I do not think it is possible to suggest a terminology which will clarify the position for the uninitiated, and conversely, those who have thought out the problem will not be troubled by semantics.

\section{Analysis of Ventulation/Perfusion Relationships in Patient Care}

It is not possible to orientate therapy on considerations of ventilation/perfusion ratios until the following conditions apply:

1. The clinical staff must be conversant with the concepts.

2. There must be a strong laboratory staff able to offer a twenty-four hour analytical service.

3. There must be a generous provision of equipment which is sufficiently close to the patients for rapid transport of samples and reporting of results.

"In practice we usually derive the alveolar dead space ventilation from measurement of the physiological dead space, but this does not alter the nature of our analysis. 
Taking the first point, we still cannot assume that graduates have been instructed in respiratory physiology during their undergraduate course to the standard required for the practice of anaesthesia. We therefore believe a strong postgraduate educational programme is necessary, and we also believe that it is helpful for postgraduates to be instructed in the handling of the relevant laboratory apparatus. For that reason all anaesthetists in Yorkshire have the opportunity to attend an annual course of lectures on the topics covered by this paper and are able to take part in a laboratory practical course which covers all the analytical techniques required for these investigations. A high percentage of our anaesthetists have already taken advantage of these facilities.

For the second point, we readily admit that our service is expensive in manpower. At the graduate level the service is, for the most part, operated by Dr. Kelman, Dr. Prys-Roberts and Dr. Greenbaum, although other members of the University Department of Anaesthesia assist in the maintenance of twenty-fourhour cover. The graduates are strongly supported by five technicians who are all trained in the considerable number of analytical techniques which are required. It also falls to them to ensure that each piece of apparatus is ready for instant use at any hour of the day or night.

The provision of equipment must be generous if the service is to be maintained. We believe that the measurement of $P_{\mathrm{O}_{2}}$ and $P_{\mathrm{CO}_{2}}$ should no longer require the services of a devoted and single-minded enthusiast. We now expect the apparatus to work; it must work for a number of operators, and it must work throughout the twenty-four hours. Accuracy must not be sacrificed in the process of transition from a research tool to a service. The apparatus must therefore be chosen with care, and a large number of spares must be carried. In some cases, spares may be stored away until required, but in the case of $P_{\mathbf{O}_{2}}$-sensing electrodes, for example, it is prudent to maintain the spare at $37^{\circ} \mathrm{C}$., with the polarizing voltage applied.

We are fortunate in having our laboratory within 50 metres of the operating theatres on one side, and of the intensive care unit on the other side. Nevertheless, we have installed intercoms and a device for transporting syringes from bedside to laboratory within seven seconds. By these means we are able to keep the more delicate pieces of apparatus within the laboratory and yet to report a provisional value for blood $P_{\mathrm{O}_{2}}$ within 90 seconds of sampling and to give the corrected value (on a gummed report form) within four and a half minutes."

We find it convenient to carry out our analyses at one of four levels of complexity. These range from a simple arterial puncture to an extensive analysis of cardio-respiratory function, including catheterization of the right heart. Our simplest procedure is collection of arterial blood with determination of $P_{\mathrm{CO}_{2}}$ and $P_{\mathrm{O}_{2}}$. As a routine we also measure haemoglobin or haematocrit and evaluate the acid-base state, but the latter is not relevant to our present discussion. The overwhelming importance of the arterial puncture is that it establishes whether, at the moment of puncture, the arterial blood-gas levels are safe for the patient,

-At this point in the Shields lecture, a 4\%-minute film was shown to illustrate the measurement of $P_{\mathrm{O}_{2}}$ from sampling to issue of the report. The film was produced by Dr. C. Prys-Roberts and the Department of Medical Photography of the University of Leeds. 
and this is why we have gone to some trouble to streamline our analysis and reporting. Although we may not know the cardiac output, it is generally possible to say what is a safe $P_{\mathrm{O}_{2}}$ for a particular haemoglobin. The arterial $P_{\mathrm{OO}_{2}}$ will define the adequacy of the alveolar ventilation in relation to the $\mathrm{CO}_{2}$ output of the patient and will exclude the possibility of $\mathrm{CO}_{2}$ narcosis in the differential diagnosis of coma. If it is assumed that the patient is in a steady state, the respiratory exchange ratio may be guessed and a rough estimate of the "ideal" alveolar $P_{\mathrm{O}_{2}}$ may be made, provided that the oxygen concentration of the inspired gas is known. This is easy enough if the patient is breathing air or 100 per cent oxygen, but it may be difficult if the patient is receiving oxygen by nasal catheter or one of the disposable masks which are currently fashionable. The "ideal" alveolar $P_{\mathrm{O}_{2}}$ may then be compared with the actual arterial $P_{\mathrm{O}_{2}}$, and it is usually possible to say from a simple arterial puncture whether the arterial $P_{\mathbf{O}_{2}}$ is roughly in accord with the ventilation, or whether there is significant venous admixture. We prefer arterial puncture to the rebreathing method of measurement of $P_{\mathrm{CO}_{2}}$ because, in our practice, oxygen levels give far more trouble than carbondioxide levels, and $P_{\mathrm{O}_{2}}$ cannot be determined by rebreathing techniques. We do not regard the detection of cyanosis as an adequate substitute for measurement of arterial $P_{\mathrm{O}_{2}}$. Our best estimate of cyanosis is made with an artificial daylight fluorescent tube with which we are able to detect $1.4 \mathrm{gm}$. of reduced haemoglobin per $100 \mathrm{ml}$. of arterial blood with a probability of 99 per cent. This corresponds to an arterial $P_{\mathrm{O}_{2}}$ of $61 \mathrm{~mm}$. $\mathrm{Hg}$ in a patient with normal haemoglobin, but only 46 $\mathrm{mm} . \mathrm{Hg}$ in a patient with a haemoglobin of $7.5 \mathrm{gm}$. per cent. Ear oximetry might be an improvement on visual assessment of cyanosis but information on performance is not available under the conditions with which we are concerned, and it is certainly a cumbersome technique. We perform approximately 1000 arterial punctures a year and do not believe that simple puncture with a small needle carries a significant hazard.

At the second level of complexity we combine the arterial sampling with collection and analysis of inspired gas. For clinical purposes, manual sampling of inspired gas is adequate, and the paramagnetic analyser has greatly simplified the analysis, without loss of accuracy. Combination of inspired oxygen concentration, arterial $P_{\mathrm{CO}_{2}}$ and arterial $P_{\mathrm{O}_{2}}$ permits an evaluation of the adequacy of oxygen therapy and also permits approximate calculation of the venous admixture effect on patients who are unfit to breathe air.

Our third level in complexity is to sample arterial blood while the inspired minute volume is being measured, the inspired gas is of known composition, and the expired gas is being sampled. This requires a unidirectional valve box and a mask unless the patient is intubated. Equipment of this nature usually causes a conscious patient to hyperventilate and so to distort his gas tensions. However, the problem does not arise if ventilation is artificial. This method of analysis permits an extensive evaluation of the patient's respiratory state. In addition to measurement of arterial $P_{\mathrm{CO}_{2}}$ and $P_{\mathrm{O}_{2}}$, it is possible to derive the following quantities: oxygen consumption, respiratory exchange ratio, physiological dead space (permitting assessment of the alveolar dead space effect), and a more precise estimation of the venous admixture. 
Our fourth level of complexity comprises the measurements outlined above, together with float catheterization of the right heart. ${ }^{10}$ This permits measurement of central venous pressure, but the principal value is for sampling of mixed venous blood. This allows the measurement of cardiac output by direct Fick and a precise estimate of "calculated venous admixture."

\section{Hypoventilation}

Hypoventilation is not a very common problem. In our experience it is most often seen in patients with severe pulmonary disease who are temporarily under the care of an anaesthetist, either for surgery or for intensive care. Occasionally, however, primary hypoventilation occurs unexpectedly and passes unnoticed. We were recently asked to see a woman with overt cyanosis when breathing air, and our analysis is shown in Figure 4. This was carried out at the first level with

\section{PATIENT UNDERVENTILATING}

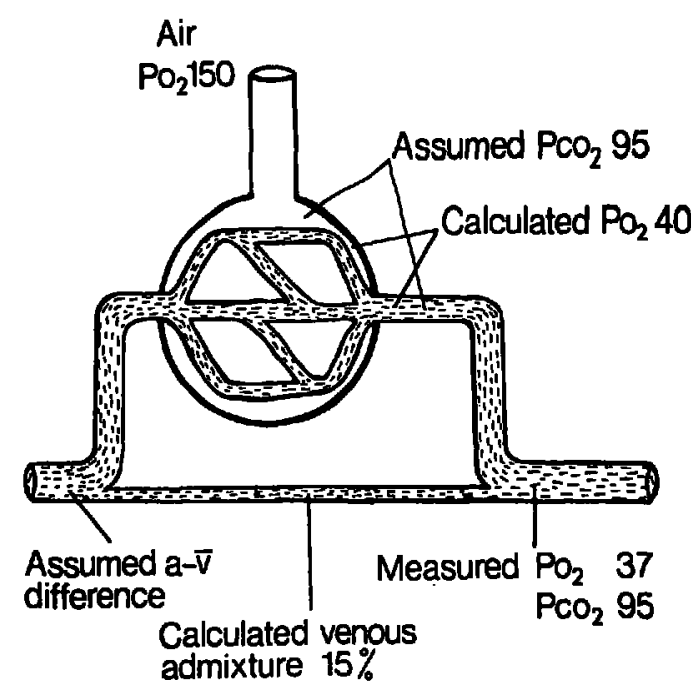

Figure 4. Analysis of a patient with hypoventilation, while breathing air. The alveolar $P_{\mathrm{CO}}$ is assumed equal to the arterial $\mathrm{PCO}_{2}$ and yields a calculated value for alveolar $P_{\mathrm{O}_{2}}$ of $40 \mathrm{~mm}$. Hg. The alveolar/arterial $P_{\mathrm{O}_{2}}$ difference is only $3 \mathrm{~mm} . \mathrm{Hg}$, and the arterial hypoxaemia is thus largely due to hypoventilation. The calculated venous admixture is 15 per cent and includes a large component due to $V / Q$ scatter when the alveolar $P_{\mathrm{O}_{2}}$ is reduced to $40 \mathrm{~mm}$. Hg.

a simple arterial puncture and no analysis of expired air. It is clear that in this case the arterial hypoxaemia was due primarily to alveolar hypoventilation, and the calculated venous admixture, although 15 per cent, only corresponded to an alveolar/arterial $P_{\mathrm{O}_{2}}$ gradient of $3 \mathrm{~mm}$. $\mathrm{Hg}$ at this level of alveolar $P_{\mathrm{O}_{2}}$. Normal $V / Q$ scatter simulates large degrees of venous admixture when the alveolar $P_{\mathrm{O}_{2}}$ is as low as $40 \mathrm{~mm}$. $\mathrm{Hg}$, for the reason shown in Figure 3. 


\section{Anaesthesia}

During anaesthesia, ventilatory considerations are now so well understood that disorders of ventilation seldom come to our attention. However, errors of distribution appear to be almost universal and constitute the major respiratory malfunction associated with anaesthesia. Alveolar dead-space ventilation appears to range from 5 to 20 per cent of total alveolar ventilation, although this may be greatly increased by pulmonary hypotension, pulmonary embolization, or mechanical restriction of pulmonary vessels. Calculated venous admixture has been widely studied, and the mean value is of the order of 10 per cent pulmonary blood flow on an assumed arterio-venous oxygen content difference of 5 vols. per cent. Authors variously ascribe this to shunt or scatter of ventilation/perfusion ratios, and it is useful to attempt a distinction between the two. This is best shown in a plot of oxygen tension against inspired oxygen concentration (Fig. 5). Assuming



Figure 5. The upper line shows the alveolar $P_{0}$ when the ventilation is ncrmal $\left(P_{\mathrm{CO}_{2}}=40 \mathrm{~mm}\right.$. Hg). The continuous curves show the arterial $P_{\mathrm{O}_{2}}$ for different degrees of shunt. The broken curve indicates the arterial $P_{\mathbf{O}_{2}}$ which would result from the degree of scatter of $V / O$ ratios shown in Figure 6 . Note that the two causes of venous admixture are indistinguishable when the patient is breathing air but that they may be distinguished by observing the effect on the arterial $P_{\mathrm{O}_{2}}$ of raising the inspired oxygen concentration.

an arterial $P_{\mathrm{CO}_{2}}$ of $40 \mathrm{~mm}$. $\mathrm{Hg}$ and the normal barometric pressure, the alveolar $P_{o_{2}}$ is shown by the upper line. Below this are shown the values for arterial $P_{\mathrm{O}_{2}}$ which would result from shunts of various magnitude (continuous curves) and also the arterial $P_{\mathrm{O}_{2}}$ which would result from gross scatter of $V / Q$ ratios (broken curve). The scatter of $V / Q$ ratios used in the example is shown in Figure 6 and was chosen to simulate a shunt of 10 per cent with the patient breathing air. Without penetrating the black box, it would be impossible to say whether the venous admixture was due to true shunt or to gross scatter of $V / Q$ ratios. Distinction is possible by studying the patient at different inspired oxygen concentrations, since the response to any increase in inspired oxygen concentration is different in the two disorders. In the case of a true shunt the alveolar/arterial 


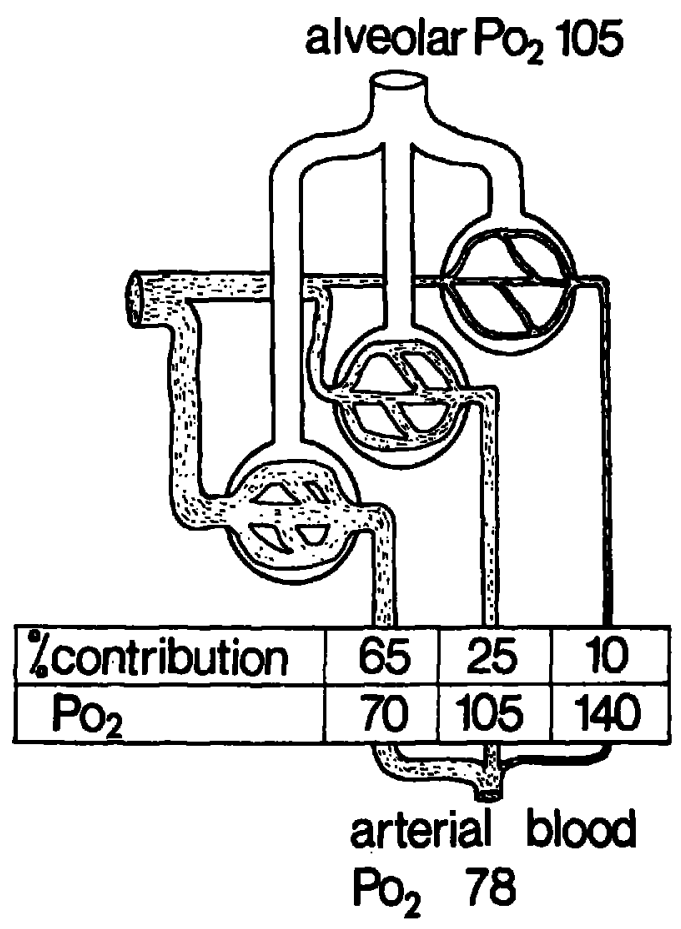

Figure 6. A model lung with gross scatter of $V / Q$ ratios used for construction of the broken curve in Figure 5. The model has no true alveolar dead space or shunt, but the scatter of $V / Q$ ratios is sufficient to simulate a 10 per cent shunt when the patient breathes air.

$P_{\mathrm{O}_{2}}$ gradient tends to increase, and in the case of gross scatter of $V / Q$ ratios, it tends to fall. In fact, in the anaesthetized patient, the arterial values fall close to the curve corresponding to a shunt of 10 per cent suggesting that the major disorder is a true shunt. However, when the alveolar $P_{\mathrm{O}_{2}}$ falls below $130 \mathrm{~mm}$. $\mathrm{Hg}$ there is a significant rise in calculated venous admixture, suggesting that a considerable degree of scatter of $V / Q$ ratio is present. ${ }^{11}$ The effect of this is usually small since most anaesthetists maintain the alveolar $P_{\mathrm{O}_{2}}$ of their patients above $130 \mathrm{~mm} . \mathrm{Hg}$, where the effect of $V / Q$ scatter on the $P_{\mathrm{O}_{2}}$ gradient is not very marked. However, at the end of operation, when the patient returns to breathing air and the alveolar $P_{\mathrm{O}_{2}}$ falls to the normal level, the effect of the $V / Q$ scatter on arterial $P_{\mathrm{O}_{2}}$ becomes significant, and we believe that it summates with the true shunt to play a major part in the production of post-operative arterial hypoxaemia. ${ }^{12}$

\section{Alveolar Contusion and Damage}

There are occasions where studies of arterial blood reveal pulmonary malfunction which is not evident from history, physical examination, or chest X-ray. Our intensive care unit recently admitted a youth who had driven his motor cycle into a bollard and was admitted with multiple minor injuries. There were no localized changes in the chest X-ray but, since he was very slightly cyanosed, an 
arterial puncture was ordered. This revealed a $P_{\mathrm{O}_{2}}$ of $55 \mathrm{~mm} . \mathrm{Hg}$ which was clearly not due to under-ventilation since the $P_{\mathrm{CO}_{2}}$ was $36 \mathrm{~mm}$. $\mathrm{Hg}$. It could be calculated that there was a venous admixture of the order of 30 per cent, but at the time no one could suggest any cause for this, and there was not the slightest evidence of atelectasis. Later that day, a second chest X-ray revealed an extensive pneumothorax, and this we took for evidence of alveolar contusion and damage, which had caused the low arterial $P_{\mathrm{O}_{2}}$ in the absence of any collateral evidence for its presence.

Discrepancies between calculated venous admixture and chest $\mathrm{X}$-ray have been widely reported during anaesthesia, and it is clear that measurement of oxygen tensions is very much more sensitive than radiography for the detection of atelectasis. Recent studies from Quebec suggest that measurement of functional residual capacity may also be more sensitive than radiography. ${ }^{13}$

\section{Fat Embolus}

Analysis of lung function is of particular value in the assessment of patients suffering from pulmonary embolization. The primary defect is an increase in alveolar dead-space ventilation but this is followed by marked venous admixture possibly as a result of pulmonary hypertension. ${ }^{14}$ These malfunctions pose separate problems in the maintenance of ventilation and in the compensation for venous admixture by oxygen therapy. Such cases are not easy to manage, and we have found it of value to make serial assessments of lung function (fourth level). Table VI shows a summary of our findings on two youths who were recently admitted with fat embolization, following fractures of long bones. ${ }^{15}$

TABLE Vl

Two Patients with Fat Embolus

\begin{tabular}{|c|c|c|}
\hline & $\begin{array}{l}\text { D.W. } \\
\text { aet. } 19\end{array}$ & $\begin{array}{l}\text { M.C. } \\
\text { aet. } 18\end{array}$ \\
\hline $\begin{array}{l}\text { Minute volume }(\mathrm{L} . / \mathrm{m} .) \\
P_{\mathrm{nco}}\left(\mathrm{mm}_{\mathrm{m}} \mathrm{Hg}\right) \\
V_{\mathrm{D}} / V_{\mathbf{x}}(\%)\end{array}$ & $\begin{array}{l}33 \\
27 \\
56\end{array}$ & $\begin{array}{l}16 \\
30 \\
46\end{array}$ \\
\hline $\begin{array}{l}\text { Inspired gas } \\
P_{\mathrm{AO}_{4}}(\mathrm{~mm} . \mathrm{Hg}) \\
P_{\mathrm{AO}}(\mathrm{mm} . \mathrm{Hg})\end{array}$ & $\begin{array}{r}\text { air } \\
108 \\
37\end{array}$ & $\begin{array}{r}\text { ajr } \\
108 \\
40\end{array}$ \\
\hline $\begin{array}{l}(\mathrm{A}-\mathrm{a}) \text { D } \mathrm{P}_{\mathrm{O}_{2}}(\mathrm{~mm} . \mathrm{Hg}) \\
\text { Calculated venous admixture }(\%) \\
\dot{V}_{\mathrm{O}_{2}}(\mathrm{ml} . / \mathrm{m} .) \\
\text { Haemoglobin }(\mathrm{gm} . / 100 \mathrm{ml}) \\
\text { Cardiac output (Fick) (L./min.) }\end{array}$ & $\begin{array}{r}\mathbf{7 1} \\
\mathbf{5 5} \\
\mathbf{5 2 0} \\
\mathbf{1 0} \\
\mathbf{9}\end{array}$ & $\begin{array}{r}68 \\
55 \\
498 \\
10 \\
14\end{array}$ \\
\hline
\end{tabular}

First, it was immediately evident that both patients were severely hypoxaemic and in urgent need of oxygen therapy. Second, the increased dead-space/tidalvolume ratio $\left(V_{\mathrm{D}} / V_{\mathrm{T}}\right)$ confirmed the diagnosis of pulmonary embolus. However, in each case, the high minute volume was sufficient to maintain the alveolar ventilation at a level which prevented hypercapnia. In fact each patient was hypocapnic, ventilation probably being driven in part by hypoxaemia. In spite 
of the hyperventilation, the arterial $P_{\mathrm{O}_{2}}$ was low with a very high alveolar/arterial $P_{\mathbf{O}_{2}}$ difference. This corresponded to a calculated venous admixture of 55 per cent in each case. It is likely that this was partly atelectasis, partly arterio-venous anastomosis, and partly due to scatter of $V / Q$ ratios, since an increase in inspired oxygen concentration raised the arterial $P_{\mathrm{O}_{2}}$ more than would be expected if the defect were entirely due to shunt. Normal arterial $P_{\mathrm{O}_{2}}$ was attained with 80 per cent oxygen for D.W. and 60 per cent oxygen for M.C. Finally we noticed that in each case oxygen consumption was at least double basal, maintenance of hyperventilation being partly responsible.

In these cases respiratory therapy was based on our findings. We appreciated that artificial ventilation would do little to improve the alveolar gas tensions but we anticipated that it would reduce the high oxygen consumptions. In fact artificial ventilation was used for D.W. and resulted in a reduction of oxygen consumption amounting to 100 per cent basal. The inspired oxygen concentration was adjusted to maintain a safe level of arterial $P_{\mathrm{O}_{2}}$. Serial studies were carried out and showed a gradual reduction of alveolar dead space and venous admixture over the next eight days.

\section{SUMMARY AND CONCLUSIONS}

Clinical examples could be multiplied, but they are intended solely to illustrate the application of studies of respiratory function to the management of patients under the care of the anaesthetist. The vast majority of patients can be adequately assessed by the anaesthetist, aided when necessary by the range of simple measuring instruments which are now available. However, there remain a small number of patients whose life is threatened by a disorder of respiratory function which cannot easily be defined without an assessment of ventilation/perfusion relationships based on analysis of arterial blood. The current range of therapeutic procedures is sufficient to enable the anaesthetist to preserve safe levels of arterial $P_{\mathrm{O}_{2}}$ and $P_{\mathrm{CO}_{2}}$ and so to prevent death from respiratory causes in all but the most extreme forms of disorder. We should therefore be able to assess the specific disorder and so to institute the appropriate form of therapy.

\section{ACKNOWLEDGMENTS}

I am indebted to Dr. J. J. L. Ablett, Professor L. P. R. Fourman, Mr. H. S. Shucksmith, and Mr. F. F. Silk for permission to present details of patients under their care.

\section{REFERENCES}

1. Commoe, J. H.; Fonster, R. E.; DuBois, A. B.; Bruscoe, W. A.; \& Carrsen, E. The Lung. 2nd ed., The Year Book Publishers, Inc., Chicago.

2. Nonn, J. F. Predictors for Oxygen and Carbon Dioxide Levels During Anaesthesia. Anaesthesia. 17: 182 (1962).

3. Pappenheimer, J. R.; Commoe, J. H.; Counnand, A.; Ferguson, J. K. W.; Filley, G. F. Fowlen, W. S.; Gray, J. S.; Helmholtz, H. F.; Otis, A. B.; Rahn, H.; \& Riley, R. L. Report of the Committee for the Standardization of Definitions and Symbols in Respiratory Physiology. Fed. Proc. 9: 602 (1950). 
4. von Hayex, H. The Human Lung. New York: Hafner (1960).

5. WEST, J. B. Regional Difference in Gas Exchange in the Lung of Erect Man. J. Appl. Physiol. 17: 893 (1962).

6. Asmussen, E. \& NnezseN, M. Alveolo-Arterial Gas Exchange at Rest and during Work at Different $\mathrm{O}_{2}$ Tensions. Acta physiol. scandinav. 50: 153 (1960).

7. Rruey, R. L.; Lifienthal, J. L.; Proemmet, D. D.; \& Franke, R. E. The Determination of the Physiologically Effective Pressures of Oxygen and Carbon Dioxide in Alveolar Air. Amer. J. Physiol. 147: 191 (1946).

8. Rm.EY, R. L. \& Counnand, A. Analysis of Factors Affecting Partial Pressure of $\mathrm{O}_{2}$ and $\mathrm{CO}_{2}$ in Gas and Blood of Lungs: Theory. J. Appl. Physiol. 4: 77 (1951).

9. RAHN, H. \& FArHI, L. E. Ventilation, Perfusion, and Gas Exchange-the $\dot{V}_{A} / \dot{Q}$ Concept. Handbook of Physiology, Section 3: Respiration. Volume 1, American Physiological Society (1964), 735-766.

10. BradiEY, R. D. Diagnostic Right-Heart Catheterisation with Miniature Catheters in Severely Ill Patients. Lancet. ii: 941 (1964).

11. NUNv, J. F. Factors Influencing the Arterial Oxygen Tension during Halothane Anaesthesia with Spontaneous Respiration. Brit. J. Anaesth. 36: 327 (1964).

12. - Influence of Age and Other Factors on Hypoxaemia in the Postoperative Period. Lancet. $i$ : 466 (1965).

13. Déry, R.; Pelletier, J.; Jacquis, A.; Claver, M.; \& Houde, J. Alveolar Collapse Induced by Denitrogenation. Canad. Anaesth. Soc. J. 12: 531 (1965).

14. Niden, A. H. \& Aviado, D. M. Effects of Pulmonary Embolism on the Pulmonary Circulation with Special Reference to Arteriovenous Shunts in the Lung. Circulation Res. 6: 67 (1956).

15. Greendaum, R.; Nunn, J. F.; Prys-Roberts, C.; Kelman, G. R.; \& Silx, F. F. Cardiopulmonary Function after Fat Embolism. Brit. J. Anaesth. 37 : 554 (1965). 